\title{
The Next Ten Years: Looking Back, Looking Forward
}

\section{Chris Glass $^{\bowtie}$ and Krishna Bista ${ }^{凶}$}

As we near our tenth year as a publication, the journal's global community continues to grow in ways we could not have imagined when we first started. We now receive over 300 submissions per year. We are proud to be among the top-20 journals in higher education according to GoogleScholar with almost 10,000 active subscribers around the world. As we prepare for the next ten years, we want to share a few updates on where we have been and where we are going. We have five major focus areas as we move forward as a publication:

- expand our global network of authors, scholars, and leaders

- design top-tier journal design and seamless editorial workflow

- build international partnerships and diversity editorial team

- create mentor pathways for emerging scholars

- develop sustainable funding and support

We have been expanding our global network of authors, scholars, and leaders. The journal has published more than 350 authors from over 45 countries. Our Editorial Team includes Associate Editors in Asia, Africa, Australia, Europe, and North America. We recently launched a new platform, Open Journals in Education (OJED), in partnership with the STARScholars Network. The OJED platform is the home of a growing network of highquality, peer-reviewed academic journals like the Journal of International Students. All journals are gold-level open access publications indexed in major academic databases and follow best practices on publication ethics outlined in the COPE Code of Conduct. We are proud to be joined by the Journal of Comparative and International Education, Higher Education Politics \& Economics, the Journal of Underrepresented \& Minority Progress, the International Journal of Multidisciplinary Perspectives in Higher Education, and the Journal of Interdisciplinary Studies in Education. We encourage you to submit to our partner publications.

We have also been working to create a top-tier journal design for our authors and readers. Our new website, ojed.org/jis, is far more than a new, enhanced visual look. It also includes the most requested features from our authors and readers, including: full-search

${ }^{凶}$ Corresponding authors: crglass@odu.edu (Chris Glass), krishna.bista@morgan.edu (Krishna Bista) 
of back issues to increase article discoverability, an 'Online First' publication of articles to website prior to print issue release, full-integration with ORCID ID for authors, article-level analytics with COUNTER compliant usage statistics for altmetrics, automatic indexing on Google Scholar when new issues are published, and the use of the Journal Article Tag Suite (JATS) XML metatags and keywords that are standard in top-tier journals. Our new manuscript submission system also improves the experience for authors and reviewers. Each published article now has its own webpage, digital object identified (DOI) listed in CrossRef, cut-and-paste ready formatted citations, and article-level statistics. When website visitors use the new search feature, they now have immediate access to a dedicated webpage with the article's title, abstract, and author bios that match their search terms.

We have also been working on building international partnerships. We recently announced a new Advisory Board (2019-2022) with prominent scholars and leaders in international education. Each member of our advisory board has published groundbreaking research in academic journals and/or popular books in the field. Members of our advisory board include: David L. Di Maria, Aneta Hayes, Howard Wang, Rahul Choudaha, Catherine Gomes, Rajika Bhandari, Helen Forbes-Mewett, Nigel Harwood, Anthony C. Ogden, Bojana Petric, Megan M. Siczek, Lily Lei Ye, Lien Pham, Ly Tran, Lydia Andrade, Stuart Tannock, Janet Ilieva, and Yingyi Ma. We are also proud to announce a new Copyediting Team led by Senior Copyeditor, Joy Bancroft.

We continue to build our legacy by creating new mentor pathways for new and emerging scholars. We are hosting a number of professional development webinars this semester in partnership with the Study Abroad and International Student SIG of the Comparative and International Education Society. Topics will include "Publication Tips: Conversation with Journal Editors", "Globally Connected Teaching and Learning," and "Study Abroad: Emerging Issues and Effective Practices." We hope these webinars introduce emerging scholars to the publication and peer review process. We are also developing new initiatives for the STARScholars Network, so we can continue to advance global social mobility using research and advocacy. Last year, over 200 dissertations were written on topics related to international students, and we have invited each of these young scholars to participate in our global community of scholars.

Finally, we have been working to develop sustainable funding to support the work of the journal. We are thankful for the financial support of Old Dominion University who is the major contributor to the journal, as well as our other supporters including the American International Recruitment Council. Old Dominion University also provides a number of graduate students who serve as Managing Editors and support key administrative functions of the journal.

As you can see, the journal continues to reach new heights. We have seen the impact, speed, and reach the journal improve - its the quality and impact, speed and publication experience, and global authorship and readership. We are listed in Scopus, ESCI, ERIC, ProQuest, OCLC, EBSCOHost, Thomson Reuters, Questia, Cengage, Scientific World Index, Scimago Journal \& Country Rank, Google Scholar Metrics, and Higher Education Abstracts. All of this would be impossible to without the dedication of readers, authors, reviewers, and an editorial team that includes people like you. Thank you for your contribution to maintaining the high standards of the journal and being part of our global community. 


\section{Author biography}

Chris Glass is the Senior Editor for the Journal of International Students and an Associate Professor in the Department of Educational Foundations and Leadership at Old Dominion University.

Krishna Bista is the Founding Editor and Editor-in-Chief for the Journal of International Studnts and an Associate Professor in the Department of Advanced Studies, Leadership and Policy at Morgan State University. 